\title{
Temperature entrainment of the circadian cuticle deposition rhythm in Drosophila melanogaster.
}

$\operatorname{AUTHOR}(S)$ :

Ito, Chihiro; Goto, Shin G; Tomioka, Kenji; Numata, Hideharu

\section{CITATION:}

Ito, Chihiro ... [et al]. Temperature entrainment of the circadian cuticle deposition rhythm in Drosophila melanogaster.. Journal of biological rhythms 2011, 26(1): 14-23

\section{ISSUE DATE:}

2011-02

URL:

http://hdl.handle.net/2433/156372

\section{RIGHT:}

(c) 2011 Sage Publications.; この論文は出版社版でありません。引用の 際には出版社版をご確認ご利用ください。; This is not the published version. Please cite only the published version. 
1 Temperature Entrainment of the Circadian Cuticle Deposition Rhythm in Drosophila

2 melanogaster

3

4 Chihiro Ito ${ }^{*}, 1$, Shin G. Goto ${ }^{*}$, Kenji Tomioka ${ }^{\dagger}$ and Hideharu Numata ${ }^{*}, 2$

$5 \quad{ }^{*}$ Graduate School of Science, Osaka City University, Osaka, Japan, ${ }^{\dagger}$ Graduate School

6 of Natural Science and Technology, Okayama University, Okayama, Japan, ${ }^{\star}$ Graduate

7 School of Science, Kyoto University, Sakyo, Kyoto, Japan

8

9 Short title: Temperature entrainment of the cuticle deposition rhythm

10

11

12

1. Current address: Chihiro Ito, Department of Neurobiology and Genetics, Biocenter,

University of Würzburg, 97074 Würzburg, Germany

2. To whom all correspondence should be addressed: Hideharu Numata, Graduate

School of Science, Kyoto University, Sakyo, Kyoto, 606-8502, Japan; e-mail: 
1 Abstract The cuticle deposition rhythm, which is observed in the apodeme of the furca

2 in the thorax, is controlled by a peripheral circadian clock in the epidermal cells and

3 entrained to light-dark cycles (LD cycles) via CRYPTOCHROME (CRY) in Drosophila

4 melanogaster. In the present study, we examined the effects of temperature cycles (TC

5 cycles) and the combination of LD and TC cycles on entrainment of the cuticle

6 deposition rhythm. The rhythm was entrained to TC cycles whose period was $28 \mathrm{~h}$. In T

$7=21$ and $24 \mathrm{~h}$, the rhythm was entrained to TC cycles in some individuals. CRY is not

8 necessary for temperature entrainment of the cuticle deposition rhythm, because the

9 rhythm in $c r y^{b}$ (lacking functional CRY) was entrained to TC cycles. Temperature

entrainment of the rhythm was achieved even when the thoraxes or furcae were cultured in vitro, suggesting that the mechanism for temperature entrainment is independent of the central clock in the brain and the site of the thermoreception resides in the epidermal cells. When LD and TC cycles with different periods were applied, the rhythm was entrained to LD cycles with a slight influence of TC cycles. Thus, the LD cycle is a stronger Zeitgeber than the TC cycle. The variance of the number of the cuticle layers decreased in the flies kept under LD and TC cycles with the same period in which the thermophase coincided with the photophase. Therefore, we conclude that LD and TC cycles synergistically entrain the rhythm. Synergistic effects of LD and TC cycles on entrainment were also observed even when the thoraxes were cultured in vitro, suggesting that the light and temperature information is integrated within the peripheral circadian system.

Key words circadian rhythm, CRYPTOCHROME, cuticle deposition, peripheral clock, phospholipase $\mathrm{C}$, temperature cycle, temperature-induced oscillation 
Circadian clocks enable organisms to program their physiology and behavior in

2 advance to coordinate with predictable daily environmental changes. In Drosophila, genetic analyses of circadian activity rhythms regulated by the central oscillator in the brain have revealed that the circadian pacemaker is a transcriptional feedback loop in which several clock gene products regulate their own and other clock genes' transcription (Allada and Chung, 2010). Briefly, PERIOD (PER) and TIMLESS (TIM) repress their own gene transcription by interfering with the activity of the transcription

8 factors CLOCK (CLK), and CYCLE (CYC) (Allada et al., 1998; Rutila et al., 1998;

$9 \quad$ Darlington et al., 1998).

In addition to the central oscillator, peripheral oscillators exist in many tissues in Drosophila (Emery et al., 1997; Plautz et al., 1997). The peripheral oscillators are light-entrainable and independent of the central oscillator (Emery et al., 1997; Giebultowicz and Hege, 1997; Giebultowicz et al., 2000; Plautz et al., 1997). Their relevance to the organism's physiology remains elusive, because they were identified based on cyclic expression of clock genes or proteins, except a small number of examples recently reported (Chatterjee et al., 2010; Krishnan et al., 2008; Krupp et al, 2010; $\mathrm{Xu}$ et al., 2008). One of the best characterized peripheral rhythms is the cuticle deposition rhythm in Drosophila (Ito et al., 2008). The exoskeleton of insects is reinforced by the alternating deposition of two layers with different chitin arrangements in the endocuticle, which is secreted from the epidermis after adult emergence (Neville, 1975). In some insects, this rhythm is shown to be circadian and is crucial for producing the correctly alternating two cuticle layers, which increases the physical strength of the cuticle (Neville, 1975). In D. melanogaster, a set of bright and dark cuticle layers in the endocuticle increases by about one per day under both light-dark cycles (LD cycles) and 
constant darkness (DD) (Ito et al., 2008), although determination of the exact free-running period is very difficult and has not been performed. Moreover, Ito et al. (2008) revealed that the cuticle deposition rhythm is governed by the peripheral circadian clock in the epidermis.

The light entrainment mechanism is well explained by entrainment and resetting of the molecular feedback loop by light-induced TIM degradation via CRYPTOCHROME (CRY) (Ceriani et al., 1999; Emery et al., 1998, 2000; Stanewsky et al., 1998). The brain and the peripheral oscillators are directly entrainable to LD cycles in vitro (Sehadova et al., 2009), suggesting that tissue-autonomous entrainment seems to be mediated by CRY, which is expressed in clock neurons in the brain and various tissues (Benito et al., 2008; Ishikawa et al., 1999; Ito et al., 2008; Ivanchenko et al., 2001; Plautz et al., 1997; Yoshii et al., 2008).

On the other hand, the mechanism of temperature entrainment, including the input pathway, has not been clarified yet. However, two genes, no receptor potential A (norpA) and no circadian temperature entrainment (nocte), seem to be involved in temperature entrainment (Glaser and Stanewsky, 2005). The peripheral oscillators are entrained to temperature cycles (TC cycles; abbreviation of thermophase-cryophase cycles) in DD and constant light in vitro, suggesting that they are tissue autonomous, like light entrainment (Glaser and Stanewsky, 2005). However, isolated brains cannot be entrained to TC cycles, rather the brain clock needs input from peripheral sensory tissues, chordotonal organs. Moreover, nocte seems to be involved in this periphery to brain signaling (Sehadova et al., 2009). Thus, both LD and TC cycles can act as Zeitgebers to entrain not only the behavioral rhythm but also molecular rhythms in peripheral tissues in vitro (Emery et al., 1997; Giebultwicz et al., 1997; Glaser and 
1 Stanewsky, 2005; Plautz et al., 1997). Two Zeitgebers, LD and TC cycles, properly

2 adjust activity rhythms in the fluctuating natural environment, and synergistically

3 entrain the molecular rhythms in the central clock (Boothroyd et al., 2007; Miyasako et

4 al., 2007; Yoshii et al., 2009). However, it is still uncertain how physiological output

5 rhythms observed in various tissues are actually affected by multiple environmental

6 cues such as LD and TC cycles.

$7 \quad$ In the present study, we examined the effects of TC cycles and combinations of

8 LD and TC cycles on entrainment of the cuticle deposition rhythm in D. melanogaster. 
Insects

Drosophila melanogaster was reared on standard medium containing wheat germ at $25 \pm 1^{\circ} \mathrm{C}$ under $12 \mathrm{~h}$ light and $12 \mathrm{~h}$ darkness (10:00 to 22:00 light). Canton-S was used as the wild-type. The following mutants were used: $\mathrm{per}^{01}, \mathrm{tim}^{01}, \mathrm{cyc}^{01}, \mathrm{Clk}^{\mathrm{Jrk}}$, $\operatorname{cry}^{b}$, norpA $^{P 24}$ (Allada et al., 1998; Hamblen-Coyle et al., 1992; Konopka and Benzer, 1971; Rutila et al., 1998; Sehgal et al., 1994; Stanewsky et al., 1998). All used flies had wild-type body color (yw+ back ground). White fluorescent light (FLR20 SW/M or FL15W, Matsushita Electric Works Ltd., Tokyo) was used for the photophase at a light intensity of $3 \mathrm{~W} / \mathrm{m}^{2}$. Newly emerged flies were collected within $6 \mathrm{~h}$ from light-on. In the present study, day 0 is defined as the $24 \mathrm{~h}$ period from light-on of the day of adult emergence, and the next $24 \mathrm{~h}$ is day 1.

\section{Histological Observation of Cuticle Growth Layers}

Newly emerged adult flies were exposed to various conditions for 6 days. Their

third furcae, which are apodemata based on the third legs and internal attachments of thoracic muscles, were used for observation of cuticle growth layers in the endocuticle because the third furca is most appropriate (Fig. 1A) (Ito et al., 2008; Johnston and Ellison, 1982). Histological preparations of the third furcae were performed in the same way as previously described (Ito et al., 2008). In brief, isolated thoraxes from fixed flies were boiled in $4 \%$ sodium hydroxide solution to remove the organs and proteins. Cleaned thoraxes were stained with $1 \% \mathrm{KMnO}_{4}$. Then, third furcae were dissected out and mounted in glycerol on a slide glass. The endocuticle layers of furcae (Fig. 1A) 
were observed as bright and dark layers after preparation under a Nomarski differential interference contrast microscope (BX50-DIG, Olympus, Tokyo) (Neville, 1983) and the number of bright layers in the endocuticle was counted.

\section{TC Cycles}

Newly emerged adult flies were exposed to TC cycles with a Zeitgeber period $(\mathrm{T})=18,21,24,28$, or $36 \mathrm{~h}$ for 6 days $(=144 \mathrm{~h})$. Each TC cycle contained equal durations of the thermophase $\left(25 \pm 1^{\circ} \mathrm{C}\right)$ and cryophase $\left(15 \pm 1^{\circ} \mathrm{C}\right)$. This schedule provided $8,7,6,5$, or 4 TC cycles, respectively, for the 6 days. The number of cuticle layers would follow the number of cycles given during $144 \mathrm{~h}$, if the rhythm is entrained to the Zeitgeber. In addition, the number of cuticle layer is one at the day of eclosion (see Fig. 1 of Ito et al., 2008). Thereby, we establish the simplified equation; y (the number of bright layers) $=1+144 \mathrm{~h} / \mathrm{x}$ (Zeitgeber period, h). TC cycles were set using an incubator-built-in thermostat driven by an electronic timer (MIR-153, Sanyo Electric, Osaka). Temperature steps were finished within $30 \mathrm{~min}$ both for increase and decrease. The background of TC cycles was DD, although the light was on only in the first thermophase of the adult stage. Flies were fixed in the thermophase on day 6 for the observation of cuticle growth layers. As a control, flies were kept at $20 \pm 1^{\circ} \mathrm{C}$ under DD for 6 days although light was on at $25 \pm 1^{\circ} \mathrm{C}$ in the first $12 \mathrm{~h}$ of day 0 . This condition is referred to as $20^{\circ} \mathrm{C} / \mathrm{DD}$ hereafter.

\section{LD Cycles}

Newly emerged norp $A^{P 24}$ adult flies were exposed to LD cycles with $\mathrm{T}=21,24$, and $28 \mathrm{~h}$ consisting of equal durations of the photophase and scotophase at $25 \pm 1^{\circ} \mathrm{C}$. In 


\section{Combination of TC and LD Cycles}

7 this regime is referred to as TC24 hereafter.

\section{Tissue Culture}

these regimes, 7, 6 or 5 cycles were given to flies for the 6 days $(=144 \mathrm{~h})$. Flies were fixed in the photophase on day 6 for the observation of cuticle growth layers. As a control, flies were kept at $25 \pm 1^{\circ} \mathrm{C}$ under DD for 6 days, although the first $12 \mathrm{~h}$ of day 0 light was on. This condition is referred to as $25^{\circ} \mathrm{C} / \mathrm{DD}$ hereafter.

Newly emerged adult flies were exposed to 9 combinations of LD cycles with T $=21-28 \mathrm{~h}$ and $\mathrm{TC}$ cycles with $\mathrm{T}=21-28 \mathrm{~h}$ for 6 days. Flies were fixed in the photophase/thermophase on day 6 for the observation of cuticle growth layers. When $\mathrm{TC}$ cycles with $\mathrm{T}=24 \mathrm{~h}$ and $\mathrm{LD}$ cycles with $\mathrm{T}=24 \mathrm{~h}$ were given, for example, this regime is referred to as TC24/LD24. In the case of $\mathrm{TC}$ cycles with $\mathrm{T}=24 \mathrm{~h}$ under DD,

Newly emerged adult flies were exposed to LD and TC cycles of which the thermophase corresponded to the photophase $(T=21-28 \mathrm{~h})$. The thoraxes or furcae were dissected out on the second photophase/thermophase. Isolated specimens were rinsed with sterilized $0.9 \%$ saline solution several times. Subsequently, isolated thoraxes or furcae were rinsed with Sheneider's Drosophila medium (GIBCO BRL, Grand Island, NY) including 1\% penicillin-streptomycin (GIBCO BRL, Grand Island, NY). Each isolated thorax was incubated in $150 \mu \mathrm{l}$ of medium and each isolated furca was incubated in a drop $(20 \mu \mathrm{l})$ of medium under TC cycles in DD (DD started from the second scotophase/cryophase) or under LD and TC cycles and for five days. These specimens were fixed in the thermophase or thermophase/photophase on day 6 , and 
1 histological preparations were performed as described above for observation of cuticle

2 growth layers in furcae. In case of thorax culture, furcae were dissected out after

3 staining.

4

5

Fig. 1, one-column width, 4 inch height.

6 


\section{RESULTS}

2

\section{Entrainment to TC Cycles in Wild-type and cry $^{\boldsymbol{b}}$ Flies}

We examined the entrainability of the cuticle deposition rhythm to TC cycles with various $\mathrm{T}$ in wild-type flies for 6 days under DD. Fig. 1B shows the number of layers in these flies. If the cuticle deposition rhythm is completely entrained to the TC cycles, the number of bright layers would change as shown by the hyperbola in the figure. In TC21, TC24 and TC28, eight, seven and six bright layers were observed in many individuals, respectively, i.e., the mean numbers of bright layers were changed along the hyperbola, although the mean value in TC24 was significantly larger than the hypothesized value ( $t$-test, $\mathrm{P}<0.001$ ). In addition, the mean numbers of bright layers in these three conditions were significantly different from the number under $20^{\circ} \mathrm{C} / \mathrm{DD}$ ( $t$-test, $P<0.05$ ). In the other conditions (TC18 and TC36), however, the numbers of bright layers were not changed with the number of given TC cycles, and were significantly different from the hypothesized values ( $t$-test, $\mathrm{P}<0.001)$, and not significantly different from the number in $20^{\circ} \mathrm{C} / \mathrm{DD}(F$-test, $P>0.05)$. The variances of the number of bright layers were smaller in TC24 and TC28 but larger in the other conditions than in $20^{\circ} \mathrm{C} / \mathrm{DD}$, although there were no significant differences $(F$-test, $P>$ 0.05). From these results, we conclude that the cuticle deposition rhythm is entrained to TC28 and to TC21 and TC24 in some individuals. In TC18 and TC36, the cuticle deposition rhythm free-runs, as in $20^{\circ} \mathrm{C} / \mathrm{DD}$. Ten of 36 individuals in $20^{\circ} \mathrm{C} / \mathrm{DD}$ showed no alternating bright and dark layers in the endocuticle. They were designated as having arrhythmic cuticle deposition (Ito et al., 2008). However, all flies subjected to TC cycles had alternating layers (see Fig. 5). 
In $c r y^{b}$ mutant flies, some individuals showed arrhythmic cuticle deposition (9/41 in TC21, $12 / 46$ in $\left.20^{\circ} \mathrm{C} / \mathrm{DD}\right)$. In TC21-28, the mean numbers of bright layers were changed in accordance with the hyperbola and not significantly different from the hypothesized values ( $t$-test, $\mathrm{P}>0.05$, Fig. $1 \mathrm{C}$ ). Thus, the cuticle deposition rhythm of $c r y^{b}$ is entrained better to TC cycles in the range of $21-28 \mathrm{~h}$ compared to wild-type flies.

In contrast, the numbers of bright layers were not changed in accordance with the hyperbola in TC18 and TC36, and were significantly different from the hypothesized values (t-test, $\mathrm{P}<0.001$, Fig. 1C).

\section{Effect of norpA Gene Mutation}

To examine the involvement of phospholipase C (PLC) in the temperature entrainment of the cuticle deposition rhythm, we examined the cuticle deposition rhythm in norp $A^{P 24}$ under LD cycles, TC cycles, $20^{\circ} \mathrm{C} / \mathrm{DD}$ and $25^{\circ} \mathrm{C} / \mathrm{DD}$. The norp $A^{P 24}$ mutant, a loss of function mutant of PLC encoded by the norpA gene, showed severe disruption of temperature entrainment of the locomotor activity rhythm in $D$. melanogaster (Glaser and Stanewsky, 2005). From the results, Glaser and Stanewsky (2005) concluded that PLC is involved in the signaling pathway between temperature reception and the circadian clock.

Fig. 2, one-column width, 3 inch height.

Some flies showed arrhythmic cuticle deposition in all the conditions examined (47.3-87.2\%; $n=39-94)$. In flies with rhythmic cuticle deposition, in LD21-28, the mean numbers of bright layers were changed in accordance with the hyperbola, 
1 although the mean number of layers was significantly higher than the hypothesized

2 value in LD28 ( $t$-test, $\mathrm{P}<0.01$, Fig. $2 \mathrm{~A}$ ). In contrast, the numbers of bright layers were not changed in accordance with the hyperbola under TC21-28, and were significantly different from the hypothesized values in TC21 and TC28 ( $t$-test, $\mathrm{P}<0.001$, Fig. 2B). There was no significant difference in the mean number of bright layers (Kruscal-Wallis

6 test, $P>0.01$, Fig. 2B). These results indicate that the cuticle deposition rhythm of $7 \quad \operatorname{norp} A^{P 24}$ flies is entrained to LD cycles but not to TC cycles.

8

Fig. 3, one-column width, 4.4 inch height

\section{Combined Effects of the TC and LD Cycles on Entrainment}

To examine the strength of LD and TC cycles as Zeitgebers and also their interaction, we gave both LD and TC cycles with different or same periods. If LD cycles are the dominant Zeitgeber, the rhythm would be entrained to LD cycles even when TC cycles with a different period were simultaneously given. In addition, if LD and TC cycles synergistically operate to entrain the cuticle deposition rhythm, the variance of the number of bright layers would be smaller under both LD and TC cycles with the same period than under either Zeitgeber alone.

A few flies showed arrhythmic cuticle deposition in TC21/LD24 and TC28/LD24 (2/42 and 1/40, respectively). In TC21/LD24 and TC21/LD28, the mean numbers of bright layers were close to the hyperbola that is the hypothesized population mean when the rhythm is entrained to LD cycles (Fig. 3A). In contrast, in the LD and TC cycles with different periods, the mean numbers of layers were significantly different from the hypothesized values for TC cycles ( $t$-test, $\mathrm{P}<0.001$, Fig. 3A). The 
same tendencies were observed in TC24/LD21, TC24/LD28, TC28/LD21, and TC28/LD24: the mean numbers of bright layers were close to the hyperbola predicting layer number in LD cycles (Fig. 3B, C). If TC cycles affect the cuticle deposition rhythm under both LD and TC cycles with different periods, the variance of the number of cuticle layers would be larger than that under LD cycles alone. The variances of the numbers of bright layers in the regimes with different periods were larger than those in LD cycles alone except in TC28/LD21, although there was a significant difference in the variance only between LD24 (see Ito et al., 2008, Fig. 1) and TC21/LD24 (F-test, P $<0.05)$. Thus, TC cycles did not entrain the rhythm under LD and TC cycles with different periods, but somewhat affected the rhythm. We therefore suggest that the LD cycle is stronger as a Zeitgeber for the rhythm than the TC cycle.

When LD and TC cycles with the same periods were given, the mean numbers of bright layers were in accordance with the given cycles (Fig. 3). The variances of the number of bright layers were significantly smaller than those under TC cycles alone (F-test, $\mathrm{P}<0.05$, see Fig. 1A), and smaller than those under LD cycles (see Fig. 1 of Ito et al., 2008 but with a significant difference only in $\mathrm{T}=21 \mathrm{~h}, \mathrm{~F}$-test, $\mathrm{P}<0.05)$. Thus, because the cuticle deposition rhythm is properly entrained to LD and TC cycles, we conclude that LD and TC cycles with the same periods synergistically entrain the cuticle deposition rhythm.

When $c r y^{b}$ flies were kept under TC24/LD24, the number of layers was $7.07 \pm$ 1.05 (mean $\pm \mathrm{SD}$ ), which is the same as that under TC cycles alone, and the variance of the number of layers was significantly smaller than that under LD cycles alone (Fig. 1; see also Fig. 5 of Ito et al., 2008). This result supports the conclusion of Ito et al. (2008) that the rhythm cannot be entrained to LD cycles in $c r y^{b}$ flies. 
Fig. 4, one-column width, 3.2 inch height

\section{Entrainment of Cuticle Deposition Rhythm In Vitro}

To examine whether the cuticle deposition rhythm is entrained to TC cycles

6 independent of the $\operatorname{clock}(\mathrm{s})$ in the brain, isolated thoraxes or furcae were cultured

7 individually in vitro within the range of $\mathrm{T}=21-28 \mathrm{~h}$. Rhythmic cuticle deposition was

8 observed in most of the thoraxes and furcae ( $>73 \%)$. Figure $4 \mathrm{~A}$, B shows the number

9 of bright layers on day 6 after adult emergence (cultured for five days) under TC21-28.

The number of bright layers was changed with the number of TC cycles given when

isolated thoraxes or furcae were cultured in vitro (Fig. 4A, B). These results suggest that

the cuticle deposition rhythm is entrained to TC cycles even in isolated thoraxes and

furcae, although the limit of entrainment was not confirmed. Therefore, we suggest that entrainment to TC cycles is accomplished independent of the clock in the brain and a thermoreception site resides in the epidermal cells.

To examine whether the synergistic effect of LD and TC cycles on entrainment occurs without intervention of the $\operatorname{clock}(\mathrm{s})$ in the brain, isolated thoraxes and furcae were cultured individually in vitro under LD and TC cycles of which the thermophase corresponded to the photophase with the same T.

The rhythm of the isolated thoraxes was entrained to LD and TC cycles (Fig. 4C). The variances of bright layers under both LD and TC cycles were always smaller than those under either LD or TC cycles alone (Figs. 4A, C, see also Fig. 2 of Ito et al.,

23 2008). There was a significant difference in the variance between TC24/LD24 and

24 LD24, TC28/LD28 and LD28, and TC28/LD28 and TC28 (F-test, $\mathrm{P}<0.05)$. 
In the furcae cultured in vitro, the variances of bright layers between TC/LD and

2 TC cycles alone were almost the same, with no significant difference (Figs. 4B, D,

3 F-test, $\mathrm{P}>0.05)$. In contrast, the variances of bright layers in TC/LD were significantly

4 smaller than that in LD24 or LD28 (Fig. 4D, F-test, P $<0.05$, see Fig. 2 of Ito et al.,

5 2008), although there was no significant difference in the variance of layers between

6 TC21/LD21 and LD21 (F-test, P > 0.05).

7

From these results, we conclude that a synergistic effect of LD and TC cycles on the entrainment occurs in isolated thoraxes but not in isolated furcae cultured in vitro. The rhythm was entrained to LD cycles in isolated thoraxes but not in isolated furcae cultured in vitro (Ito et al., 2008). From these results, the authors suggested that the photoreceptive site for the photic entrainment of the cuticle deposition rhythm resides in thorax, but not in the epidermis. The current results support this suggestion.

Fig. 5, one-column width, 2.8 inch height

\section{The Cuticle Deposition Rhythm in the Clock Mutants under TC Cycles}

When $\mathrm{T}$ was close to $24 \mathrm{~h}$, arrhythmic mutant flies carrying per $^{01}$ and tim $^{01}$ showed rhythmic cuticle deposition induced by LD cycles, but flies carrying $\operatorname{cyc}^{01}$ and Clk ${ }^{\text {Jrk }}$ did not (Ito et al., 2008). From these facts, it was concluded that a per- and tim-independent circadian oscillator that involves $C l k$ and $c y c$ as essential components is involved in the cuticle deposition rhythm. To test whether TC cycles are also able to induce the circadian rhythmicity as well as LD cycles, the endocuticle was observed using arrhythmic mutant flies carrying $\mathrm{per}^{01}, \mathrm{tim}^{01}, \mathrm{cyc}^{01}$, or $\mathrm{Clk}^{\mathrm{Jrk}}$ in TC cycles under DD. Most mutant flies showed arrhythmic cuticle deposition under $20^{\circ} \mathrm{C} / \mathrm{DD}$ (Fig. 5). 
1 However, the results under TC cycles were different between $\operatorname{per}^{01}$ and the other three

2 mutants. In $\operatorname{tim}^{01}, \mathrm{cyc}^{01}$, and $C \mathrm{k}^{\mathrm{Jrk}}$ flies, the proportion of flies with rhythmic cuticle

3 deposition was higher under TC cycles than under $20^{\circ} \mathrm{C} / \mathrm{DD}$. TC24 was the strongest for

4 induction of rhythmic cuticle deposition (Fig. 5). There were significant differences in

5 the proportion of flies with rhythmic cuticle deposition between TC24 and 20 $\mathrm{C} / \mathrm{DD}$ in

$6 \operatorname{tim}^{01}$, cyc $^{01}$, and $C l k^{J r k}$ (Fig. 5, Tukey multiple comparison for proportions, $\mathrm{P}<0.05$ ). In

7 per $^{01}$, however, TC cycles did not induce rhythmicity, and there was no significant

8 difference among any of the conditions examined (Fig. 5, chi-square test, $\mathrm{P}>0.05$ ). In

9 addition, the rhythm did not entrain to TC cycles in any of the four mutants with

10 rhythmic cuticle deposition (data not shown), indicating that the rhythm induced by TC

11 cycles is not caused by a direct response to temperature changes. These results suggest

12 that $\operatorname{tim}^{01}$, cyc $^{01}$, and $\mathrm{Clk}^{\text {Jrk }}$ flies have a weak oscillation that is induced by TC cycles

13 and requires per. 


\section{DISCUSSION}

Temperature Entrainment

The present study revealed that the cuticle deposition rhythm, which is controlled by the peripheral circadian clock (Ito et al., 2008), is entrained to TC cycles in D. melanogaster. This is not a direct response to temperature changes but rather is regulated by an endogenous clock mechanism because the rhythm had limits of entrainment in the Zeitgeber period (Fig. 1B). Moreover, clock mutants affected the rhythm, supporting that the rhythm is temperature-entrained rather than temperature-driven (Fig. 5). However, the cryophase temperature of $15^{\circ} \mathrm{C}$ used in the present study is lower than those in previous studies in Drosophila (e.g., Glaser and Stanwsky 2005, Yoshii et al., 2002), and the effects of other TC cycles should also be examined in future.

In most insect circadian rhythms, oscillators are entrained by both LD and TC cycles but the LD cycle is the stronger Zeitgeber (Saunders, 2002). In some cases, however, the TC cycle is a predominant Zeitgeber: The adult eclosion rhythm in the tsetse fly Glossina morsitans is entrained by TC cycles rather than LD cycles (Zdárek and Denlinger, 1995) and the eclosion rhythm of two Japanese strains of Cymomyza costata collected in Sapporo shows a higher entrainability to TC cycles with a $4{ }^{\circ} \mathrm{C}$ difference than to LD cycles (Lankinen and Riihimaa, 1997). However, the entrainability to simultaneously applied LD and TC cycles has not been investigated in peripheral oscillators. The present results indicate that the LD cycle is a much stronger Zeitgeber than the TC cycle in cuticle deposition rhythms. The dominant effect of the LD cycle as a Zeitgeber on the peripheral circadian rhythm was also reported in the 
timing of sperm release in the moth Spodoptera littoralis (Syrova et al., 2003).

\section{Input Pathway for Temperature Entrainment}

We showed here that the cuticle deposition rhythm is entrained to TC cycles even when furcae are cultured in vitro (Fig. 4B). This fact strongly suggests that both thermoreception and temperature entrainment occur in the epidermal cells. It is thus unlikely that the nocte gene known for thermoperiodic entrainment of locomotor rhythm is involved in the temperature entrainment of cuticle deposition rhythms, since it is expressed in chordotonal organs and external sense organs (Sehadova et al., 2009). CRY also seems not to be involved in the temperature entrainment because the cuticle deposition rhythm was clearly entrained in $c r y^{b}$ mutant flies (Fig.1C). This view is also supported by the previous reports that $c r y^{b}$ showed oscillations of clock gene and protein expression synchronized to TC cycles in various tissues (Glaser and Stanewsky, 2005; Stanewsky et al., 1998). However, CRY seems to affect the ability of entrainment to TC cycles, because the entrainment ability was improved by the absence of CRY (Fig. 1C). Glaser and Stanewsky (2007) discussed that peripheral oscillators of $D$. melanogaster are better entrained to TC cycles at a molecular level under CRY deficient conditions both in a wild-type under constant light and in the $c r y^{b}$ mutant. Our results confirmed this at a level of physiological output.

The present study revealed that the cuticle deposition rhythm of norp $A^{P 24}$ mutant flies lacking functional PLC failed to entrain to TC cycles (Fig. 2B), suggesting that norpA is involved in the temperature entrainment of the rhythm. Our finding is consistent with the previous report that in $n o r p A^{P 24}$ flies circadian rhythms in clock gene expression and behavior did not entrain to TC cycles (Glaser and Stanewsky, 2005). 
1 Thus, PLC may contribute to the signaling between the thermoreceptor and the

2 molecular oscillator in the epidermal cells because norpA is expressed in a variety of

3 tissues including the adult thorax (Ivanchenko et al., 2001; Zhu et al., 1993), although

4 we have not examined the expression of norpA in the epidermal cells.

5

6 Synergistic Entrainment Effect of Light and Temperature.

7

The present study showed synergistic effects of LD and TC cycles for the entrainment in the cuticle deposition rhythm when LD and TC cycles are given with the photophase coinciding with the thermophase (Fig. 3). Our findings provide a reasonable interpretation for the previous report: The endocuticlar layers are useful for estimation of ages in field-caught Drosophila because the cuticle growth layers increase by about one per day after eclosion. The age estimation is remarkably accurate in flies kept under LD and TC cycles $\left(22-14{ }^{\circ} \mathrm{C}\right)$ with the same periods in which the thermophase coincided with the photophase, in comparison with that in flies kept under LD or TC cycles alone (Johnston and Ellison, 1982).

The synergistic entraining effects of LD and TC cycles were observed even when thoraxes were cultured in vitro (Fig. 4C). This result indicates that information of LD and TC cycles is integrated by the peripheral circadian system within the thorax after it is received through separate pathways: CRY is involved in the light pathway and a receptor coupled transduction cascade including PLC in the temperature pathway. A cooperative effect of LD and TC cycles has been shown for entrainment of the locomotor rhythm also (Boothroyd et al., 2007; Miyasako et al., 2007; Yoshii et al., 2009). However, for both central and peripheral clocks, it remains to be elucidated how the two zeitgeber signals are integrated at the cellular level. 


\section{Temperature Induced Rhythm in Arrhythmic Mutants}

The present study revealed that TC cycles induce rhythmic cuticle deposition in certain fractions of $\operatorname{tim}^{01}, C l k^{J r k}$ and $c y c^{01}$ flies (Fig. 5). The rhythm is not a simple response to acute temperature changes, but rather is based on an endogenous oscillatory mechanism because the rhythm was most frequently induced in TC24 (Fig. 5). It is thus likely that there is a tim-, Clk- or cyc-independent weak circadian oscillator that is driven under TC cycles. This oscillator would have been damped immediately under DD (Fig. 5). Cuticle deposition of per ${ }^{01}$ was arrhythmic both in DD and in all the TC cycles examined, suggesting that per should be an essential component for the tim-, Clkor cyc-independent, temperature-dependent circadian oscillator for the cuticle deposition rhythm. This suggestion should be confirmed by a rescue experiment of these clock genes in future. Locomotor rhythms are also known to be induced by TC cycles in per $^{0}$ and tim $^{0}$ arrhythmic mutant flies, but the rhythm requires Clk and cyc (Yoshii et al., 2002, 2007), suggesting that the mechanisms for rhythm induction by TC cycles differ between the central and peripheral oscillators.

LD24 is known to induce a rhythmic cuticle deposition in per $^{0}$ and $\operatorname{tim}^{0}$ mutant flies and the LD cycles induced per- and tim-independent oscillation need Clk and cyc to operate (Ito et al., 2008). Thus, LD and TC cycles may exert their influence on different variables of the oscillatory machinery to induce the cuticle deposition rhythm in those arrhythmic mutant flies. 


\section{ACKNOWLEDGMENT}

2

3 We thank Elizabeth Nakajima for linguistic corrections.

\section{4}




\section{REFERENCES}

Allada R and Chung BY (2010) Circadian organization of behavior and physiology in Drosophila. Annu Rev Physiol 72:26.1-26.20.

Allada R, White NE, So WV, Hall JC, and Rosbash M (1998) A mutant Drosophila homolog of mammalian Clock disrupts circadian rhythms and transcription of period and timeless. Cell 93:791-804.

Benito J, Haul JH, Roman GW, and Hardin PE (2008) The blue-light photoreceptor CRYPTOCHROME is expressed in a subset of circadian oscillator neurons in the Drosophila CNS. J Biol Rhythms 23:296-307.

Boothroyd CE, Wijnen H, Naef F, Saez L, and Young MW (2007) Integration of light and temperature in the regulation of circadian gene expression in Drosophila. PLoS Genet 3:492-507.

Chatterjee A, Tanoue S, Houl JH, and Hardin PE (2010) Regulation of gustatory physiology and appetitive behavior by the Drosophila circadian clock. Curr Biol 20:300-309.

Ceriani MF, Darligton TK, Staknis D, Más P, Petti AA, Weitz CJ, and Kay SA (1999) Light-dependent sequestration of TIMELESS by CRYPTOCHROME. Science 285:553-556.

Darlington TK, Wager-Smith K, Ceriani MF, Staknis D, Gekakis A, Steeves TDL, Weitz CJ, Takahashi JS, and Kay SA (1998) Closing the circadian loop: CLOCK-induced transcription of its own inhibitors per and tim. Science 280:1599-1603.

Emery IF, Noveral JM, Jamison CF, and Siwicki KK (1997) Rhythms of Drosophila 
period gene expression in culture. Proc Natl Acad Sci USA 94:4092-4096.

Emery P, So WV, Kaneko M, Hall JC, and Rosbash M (1998) CRY, a Drosophila clock and light-regulated cryptochrome, is a major contributor to circadian rhythm resetting and photosensitivity. Cell 95:669-679.

Emery P, Stanewsky R, Helfrich-Förster C, Emery-Le M, Hall JC, and Rosbash M. (2000) Drosophila CRY is a deep brain circadian photoreceptor. Neuron 26:493-504.

Giebultowicz JM and Hege DM (1997) Circadian clock in Malpighian tubules. Nature 386:664.

Giebultowicz JM, Stanewsky R, Hall JC, and Hege DM (2000) Transplanted Drosophila excretory tubules maintain circadian clock cycling out of phase with the host. Curr Biol 10:107-110.

Glaser FT and Stanewsky R (2005) Temperature synchronization of the Drosophila circadian clock. Curr Biol 15:1352-1363.

Glaser FT and Stanewsky R (2007) Synchronization of the Drosophila circadian clock by temperature cycles. Cold Spring Harb Symp Quant Biol 72:233-242.

Hamblen-Coyle MJ, Wheeler DA, Rutila JE, Rosbash M, and Hall JC (1992) Behavior of period altered circadian rhythm mutants of Drosophila in light:dark cycles (Diptera: Drosophilidae). J Insect Behavior 5:417-446.

Ishikawa T, Matsumoto A, Kato Jr T, Togashi S, Ryo H, Ikenaga M, Todo T, Ueda R, and Tanimura T (1999) DCRY is a Drosophila photoreceptor protein implicated in light entrainment of circadian rhythm. Genes Cells 4:57-65.

Ito C, Goto SG, Shiga S, Tomioka K, and Numata H (2008) Peripheral circadian clock for the cuticle deposition rhythm in Drosophila melanogaster. Proc Natl Acad 
Sci USA 105: 8446-8451.

Ivanchenko M, Stanewsky R, and Giebultowicz JM (2001) Circadian photoreception in Drosophila: function of cryptochrome in peripheral and central clocks. J Biol Rhythms 16: 205-215.

Johnston JS and Ellison JR (1982) Exact age determination in laboratory and field-caught Drosophila. J Insect Physiol 28:773-779.

Konopka RJ and Benzer S (1971) Clock mutants of Drosophila melanogaster. Proc Natl Acad Sci USA 68:2112-2116.

Krishnan P, Chatterjee A, Shintaro T, and Hardin PE (2008) Spike amplitude of single-unit responses in antennal sensillae is controlled by the Drosophila circadian clock. Curr Biol 18:803-807.

Krupp JJ, Kent C, Billeter JC, Azanchi R, So AKC, Schonfeld JA, Smith BP, Lucas C, and Levine D (2008) Social experience modifies pheromone expression and mating behavior in male Drosophila melanogaster. Curr Biol 18:1373-1383.

Lankinen P and Riihimaa A (1997) Effects of temperature on weak circadian eclosion rhythmicity in Chymomyza costata (Diptera: Drosophilidae). J Insect Physiol $43: 251-260$.

Miyasako Y, Umezaki Y, and Tomioka K (2007) Separate sets of cerebral clock neurons are responsible for light and temperature entrainment of Drosophila circadian locomotor rhythms. J Biol Rhythms 22:115-126.

Neville AC (1975) Biology of the Arthropod Cuticle, Springer, Berlin.

Neville AC (1983) Daily cuticular growth layers and the teneral stage in adult insects: a review. J Insect Physiol 29:211-219.

Plautz JD, Kaneko M, Hall JC, and Kay SA (1997) Independent photoreceptive 
circadian clocks throughout Drosophila. Science 278:1632-1635.

Rutila JE, Suri V, Le M, So WV, Rosbash M, and Hall JC (1998) CYCLE is a second bHLH-PAS clock protein essential for circadian rhythmicity and transcription of Drosophila period and timeless. Cell 93:805-814.

Saunders DS (2002) Insect Clocks, 3rd Edition, Elsevier, Amsterdam.

Sehadova H, Glaser FT, Gentile C, Simoni A, Giesecke A, Albert JT, and Stanewsky R (2009) Temperature entrainment of Drosophila's circadian clock involves the gene nocte and signaling from peripheral sensory tissues to the brain. Neuron 64:251-266.

Sehgal A, Price JL, Man B, and Young MW (1994) Loss of circadian behavioral rhythms and per RNA oscillations in the Drosophila mutant timeless. Science 263:1603-1606.

Stanewsky R, Kaneko M, Emery P, Beretta B, Wager-Smith K, Kay SA, Rosbash M, and Hall JC (1998) The $c r y^{b}$ mutation identifies cryptochrome as a circadian photoreceptor in Drosophila. Cell 95:681-692.

Syrova Z, Sauman I, and Giebultowicz JM (2003) Effects of light and temperature on the circadian system controlling sperm release in moth Spodoptera littoralis. Chronobiol Int 20:809-821.

Xu K, Zheng X, and Sehgal A (2008) Regulation of feeding and metabolism by neuronal and peripheral clocks in Drosophila. Cell Metab 8:289-300.

Yoshii T, Fujii K, and Tomioka K (2007) Induction of Drosophila behavioral and molecular circadian rhythms by temperature steps in constant light. J Biol Rhythms 22:103-14. 
1 Yoshii T, Sakamoto M, and Tomioka K (2002) A temperature-dependent timing

2

3

4 mechanism is involved in the circadian system that drives locomotor rhythms in the fruit fly Drosophila melanogaster. Zool Sci 19:841-850.

Yoshii T, Todo T, Wülbeck C, Stanewsky R, and Helfrich-Förster C (2008) Cryptochrome is present in the compound eyes and a subset of Drosophila's clock neurons. J Comp Neurol 508:952-966.

Yoshii T, Vanin S, Costa R, and Helfrich-Förster C (2009) Synergic entrainment of Drosophila's circadian clock by light and temperature. J Biol Rhythms 24 : $452-464$.

Zdárek J and Denlinger DL (1995) Changes in temperature, not in photoperiod, control the pattern of adult eclosion in the tsetse, Glossina morsitans. Physiol Entomol 20:362-366.

Zar JH (1999) Biostatistical Analysis, 4th ed., Prentice-Hall, Upper Saddle River, NJ, pp 228-229, 563-565.

Zhu L, McKay RR, and Shortridge RD (1993) Tissue-specific expression of phospholipase C encoded by the norpA gene of Drosophila melanogaster. J Biol Chem 286:15994-16001. 
1 Figure 1. Effect of TC cycles with various periods on the cuticle deposition rhythm in

2 wild-type and $c r y^{b}$ mutant of Drosophila melanogaster. Ventral view of a fly (A, left),

3 sagital view of a third furca (A, middle), and cuticle growth layers (A, right) are shown.

4 The circle indicates the location of the third furca. Wild-type (B) and $c r y^{b}$ mutant (C)

$5 \quad$ flies were kept under TC cycles with $\mathrm{T}=18-36 \mathrm{~h}$ of which the background was DD

6 (light was on in the first thermophase) for 6 days. As a control, flies were kept under

7 DD at $20^{\circ} \mathrm{C}\left(20^{\circ} \mathrm{C} / \mathrm{DD}\right.$; the first $12 \mathrm{~h}$ on day 0 was in light at $\left.25^{\circ} \mathrm{C}\right)$ for 6 days. Some

8 individuals in wild-type and $c r y^{b}$ showed arrhythmic cuticle deposition (B; 10/36 in DD,

$9 \mathrm{C} ; 9 / 41$ in $\mathrm{T}=21 \mathrm{~h}, 12 / 46$ in $\left.20^{\circ} \mathrm{C} / \mathrm{DD}\right)$. The mean $\pm \mathrm{SD}$ of the number of layers in the rest of the individuals is shown in these conditions. Hyperbola: $y=1+144 / x$ is the simplified equation when the rhythm completely entrains to the given TC cycles. Asterisks indicate significant differences between the mean of the number of bright layers and hypothesized mean (***, $\mathrm{P}<0.001$ by $t$-test, Zar, 1999). $\mathrm{n}=26-46$.

Figure 2. Effects of a norpA gene mutation on the entrainment of the cuticle deposition rhythm in Drosophila melanogaster. Flies were kept under LD cycles with $\mathrm{T}=21-28$ or $\mathrm{DD}\left(25^{\circ} \mathrm{C} / \mathrm{DD}\right.$; light was on in the first $12 \mathrm{~h}$ of day 0$)$ at $25^{\circ} \mathrm{C}(\mathrm{A})$, and under $\mathrm{TC}$ cycles with $\mathrm{T}=21-28$ of which the background was DD (light was on in the first thermophase) or DD at $20^{\circ} \mathrm{C}\left(20^{\circ} \mathrm{C} / \mathrm{DD}\right.$; the first $12 \mathrm{~h}$ was in light at $\left.25^{\circ} \mathrm{C}\right)(\mathrm{B})$ for 6 days. Because some individuals showed arrhythmic cuticle deposition (A; 34/65 in $\mathrm{T}=21 \mathrm{~h}, 49 / 71$ in $\mathrm{T}$

$21=24 \mathrm{~h}, 19 / 39$ in $\mathrm{T}=28 \mathrm{~h}, 34 / 51$ in $25^{\circ} \mathrm{C} / \mathrm{DD}, \mathrm{B} ; 54 / 88$ in $\mathrm{T}=21 \mathrm{~h}, 26 / 55$ in $\mathrm{T}=24 \mathrm{~h}$, $45 / 66$ in $\mathrm{T}=28 \mathrm{~h}, 82 / 94$ in $\left.20^{\circ} \mathrm{C} / \mathrm{DD}\right)$, the mean $\pm \mathrm{SD}$ of the number of layers in the rest of the individuals is shown. Asterisks indicate significant differences between the mean of the number of bright layers and hypothesized mean (**, $\mathrm{P}<0.01$; ***, $\mathrm{P}<0.001$ by 
$t$-test, Zar, 1999). In (B), there was no significant difference in the mean of the number of bright layers among the four conditions (Kruscal-Wallis test, $P>0.05$ ). $\mathrm{n}=12-34$.

Figure 3. Combined effects of LD and TC cycles with various periods on the cuticle deposition rhythm in wild-type Drosophila melanogaster. (A) TC21 and LD21-28, (B) TC24 and LD21-28, (C) TC28 and LD21-28 were combined. The number of bright layers in the endocuticle on day 6 is shown as the mean \pm SD. Because some individuals showed arrhythmic cuticle deposition (A; 2/42 in TC21LD24, C; 1/40 in TC28LD24), the mean $\pm \mathrm{SD}$ of the number of layers in the rest of the individuals is shown in these conditions. Hyperbola: $y=1+144 / x$ is the simplified equation when the rhythm completely entrains to the given LD cycles. Horizontal equation: $y=7.9$ in (A), $y=7.0$ in (B) and $y=6.1$ in (C) are the simplified equations when the rhythm completely entrains to the given TC cycles, respectively. Symbols in the upper and lower rows indicate statistical differences between the mean of the number of bright layers and hypothesized mean under TC cycles, and between the mean of the number of bright layers and hypothesized mean under LD cycles, respectively (ns, $\mathrm{P}>0.05 ;$ *, $\mathrm{P}<0.05$; ***, $\mathrm{P}<0.001$ by $t$-test, Zar, 1999). $\mathrm{n}=30-47$.

Figure 4. Entrainment of the cuticle deposition rhythm to TC cycles and combinations of LD and TC cycles in vitro. Newly emerged flies were kept under LD and TC cycles with the same T lengths of 21-28 h, of which the thermophase corresponded to the photophase. Isolated thoraxes $(\mathrm{A}, \mathrm{C})$ or furcae $(\mathrm{B}, \mathrm{D})$ were cultured in vitro from the second thermophase/photophase. The background of TC cycles became DD from the second cryophase (A, B) or LD and TC cycles with the same T lengths of 21-28 h 
1 continued (C, D). Some individuals showed the arrhythmic cuticle deposition (A; 5/53

2 in $\mathrm{T}=21 \mathrm{~h}, 9 / 55$ in $\mathrm{T}=24 \mathrm{~h}, 11 / 59$ in $\mathrm{T}=28 \mathrm{~h}, \mathrm{~B} ; 8 / 45$ in $\mathrm{T}=21 \mathrm{~h}, 18 / 77$ in $\mathrm{T}=24 \mathrm{~h}$,

$36 / 48$ in $\mathrm{T}=28 \mathrm{~h}, \mathrm{C} ; 7 / 56$ in $\mathrm{T}=21 \mathrm{~h}, 4 / 43$ in $\mathrm{T}=24 \mathrm{~h}, 5 / 66$ in $\mathrm{T}=28 \mathrm{~h}, \mathrm{D} ; 5 / 64$ in $\mathrm{T}=$

$421 \mathrm{~h}, 4 / 62$ in $\mathrm{T}=24 \mathrm{~h}, 7 / 57 \mathrm{in} \mathrm{T}=28 \mathrm{~h}$ ), and the mean $\pm \mathrm{SD}$ of the number of layers on

5 day 6 in the other individuals with the rhythmic cuticle deposition is shown in these

6 cases. Hyperbola: see legend for Fig. 1. Asterisks indicate significant differences

7 between the mean number of bright layers and the hypothesized value (**; $P<0.01$,

$8 \quad t$-test, Zar, 1999). $\mathrm{n}=33-61$.

9

10 Figure 5. Effects of clock gene mutations on temperature entrainment of the cuticle deposition rhythm in Drosophila melanogaster. Newly emerged flies were kept under TC cycles with $\mathrm{T}=21-28 \mathrm{~h}$ or DD at $20{ }^{\circ} \mathrm{C}\left(20^{\circ} \mathrm{C} / \mathrm{DD}\right.$; light was on at $25^{\circ} \mathrm{C}$ in the first $12 \mathrm{~h}$ of day 0 ). The ordinate shows the percentage of the individuals with rhythmic

14 cuticle deposition on day 6 . The bars with the same letters in each of the wild-type, $c r y^{b}$, $15 \operatorname{tim}^{01}$, cyc $^{01}$, and $C l k^{J r k}$ were not significantly different (Tukey-type multiple

16 comparisons for proportions, $P>0.05$, Zar, 1999). There was no significant difference

17 among the four conditions examined for $\operatorname{per}^{01}\left(P>0.05, \chi^{2}\right.$-test $) . \mathrm{n}=30-69$. 
A
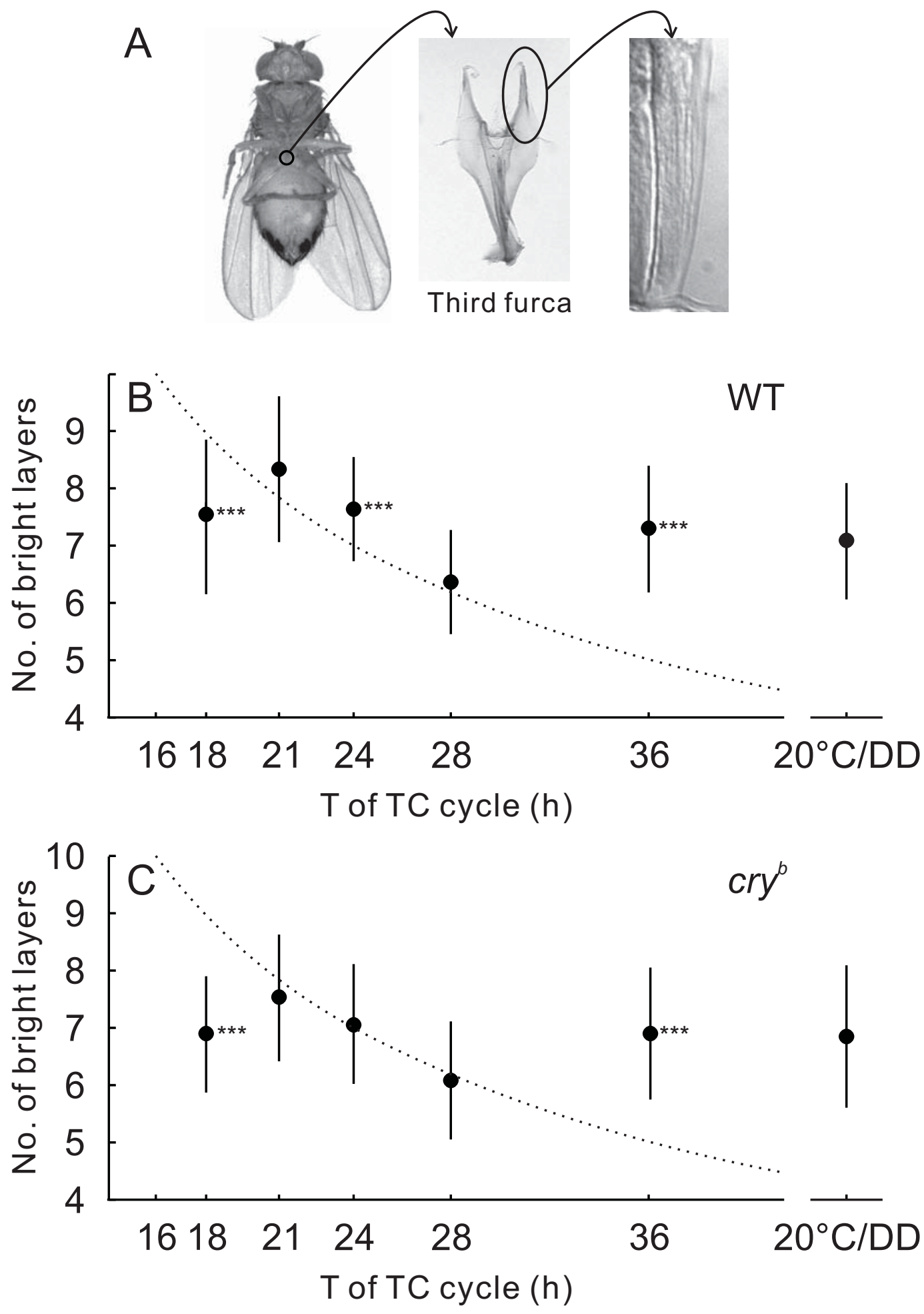

Fig. 1. 

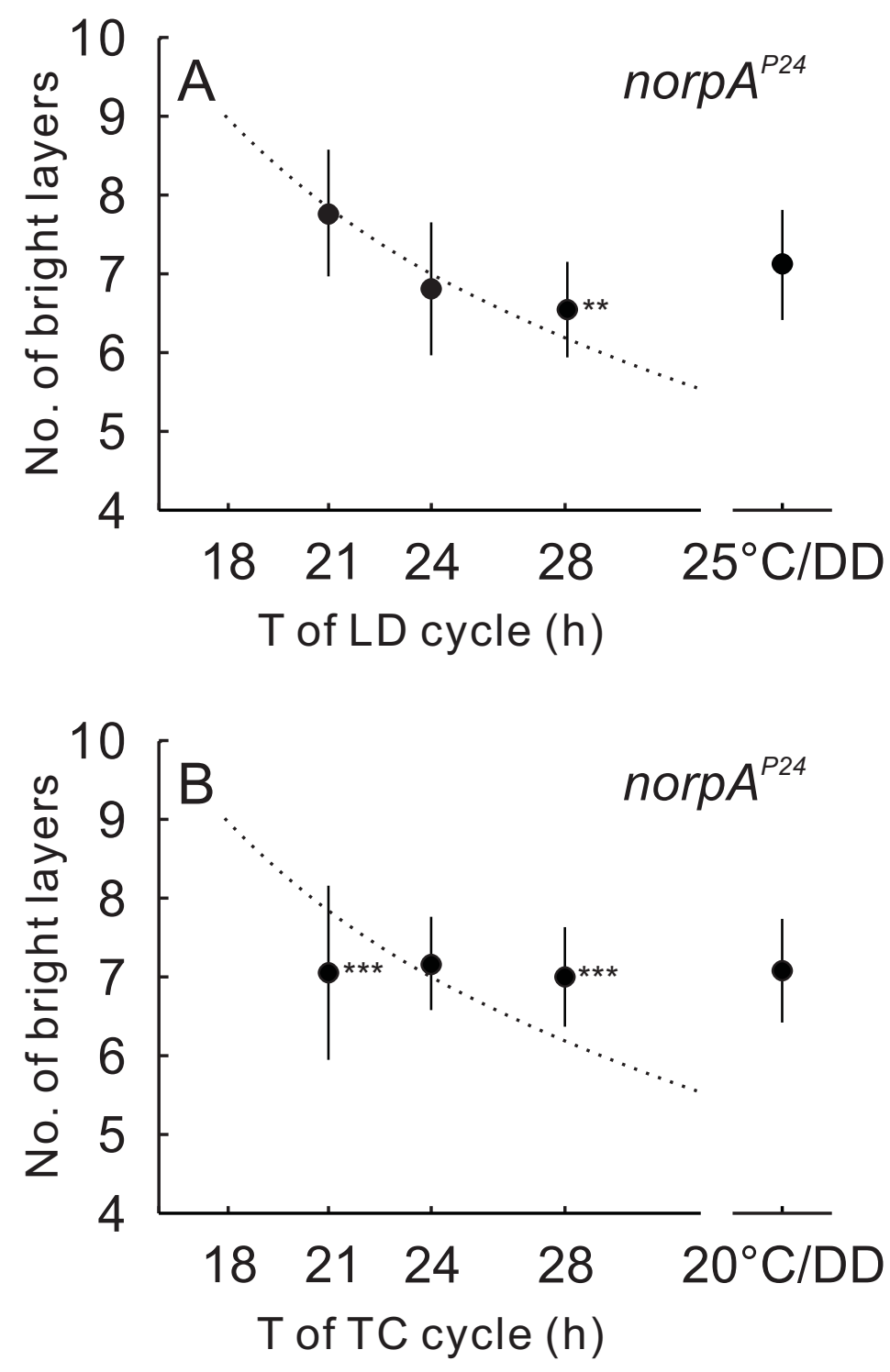

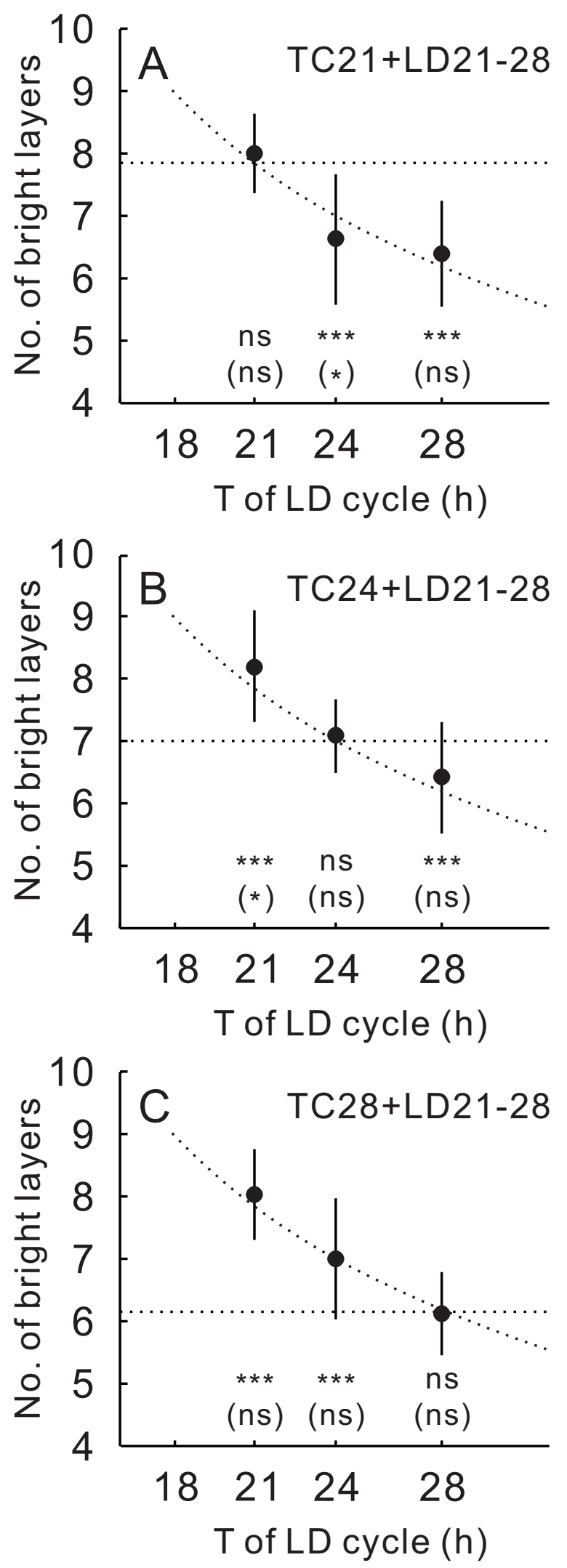

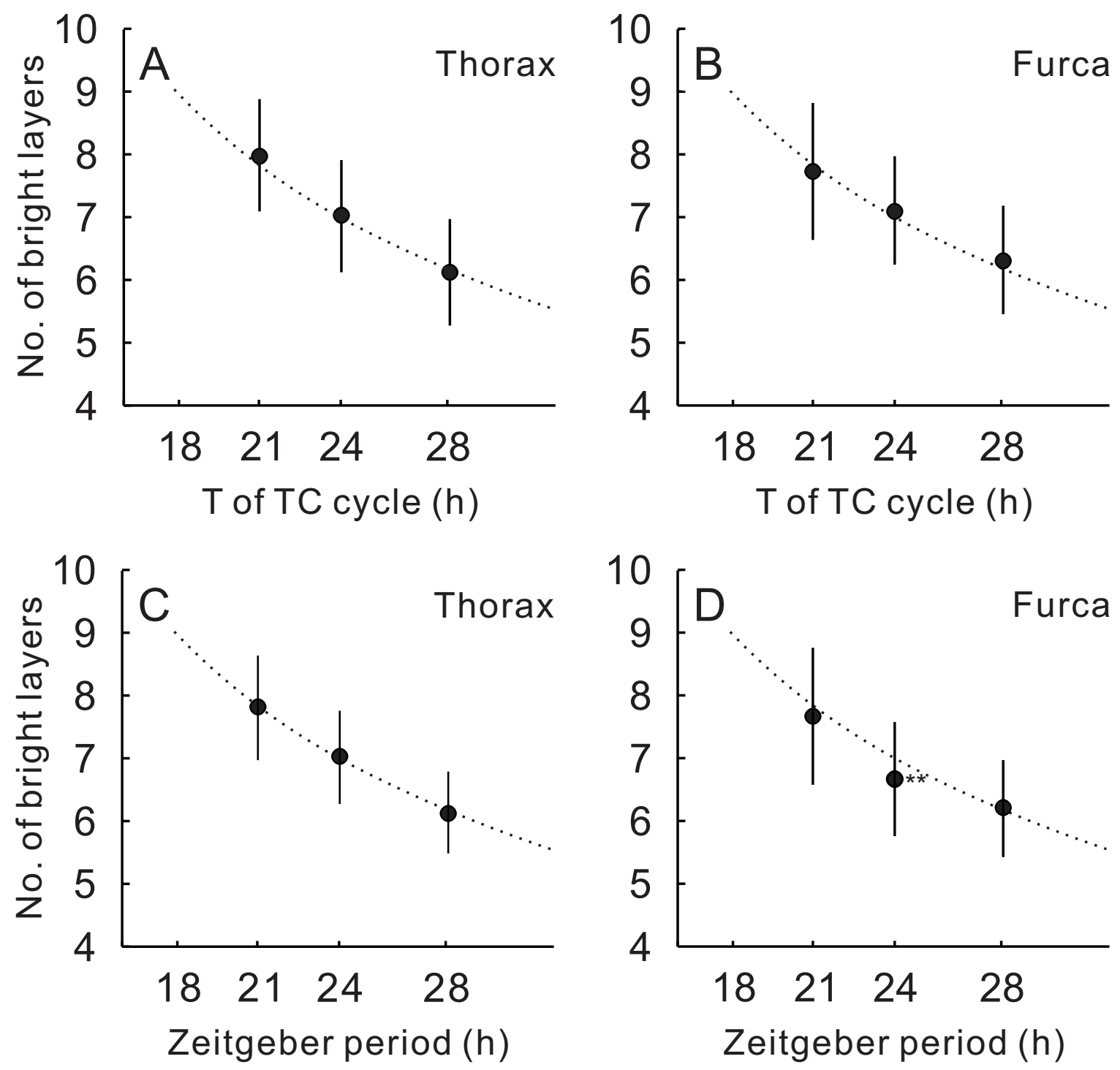

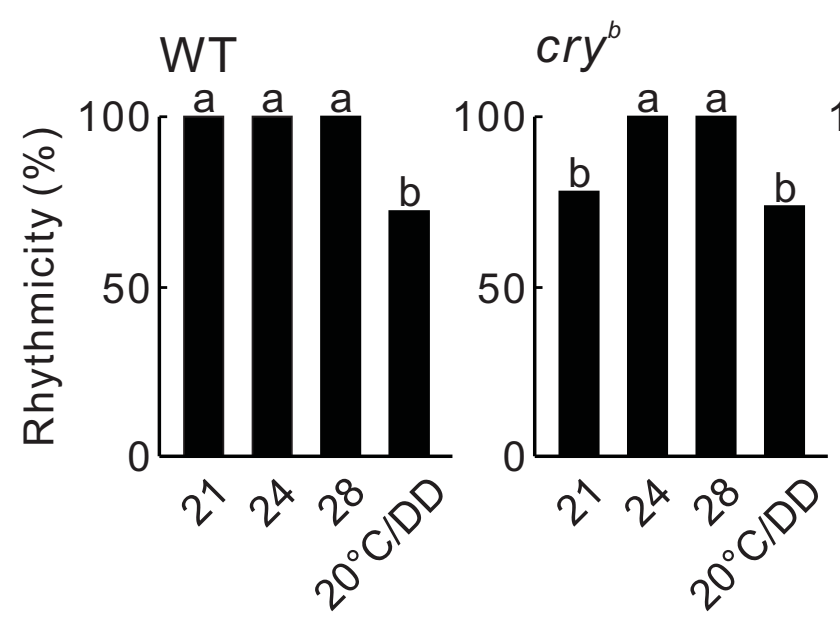

per $^{01}$

cyc $^{01}$

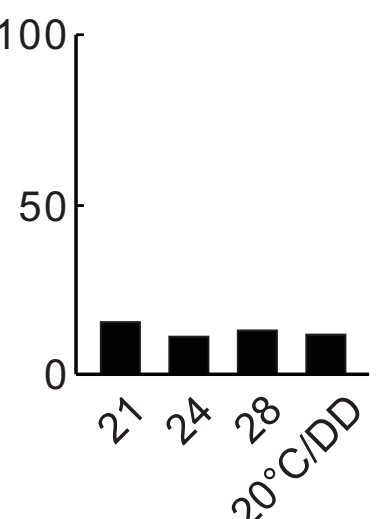

$\operatorname{tim}^{01}$
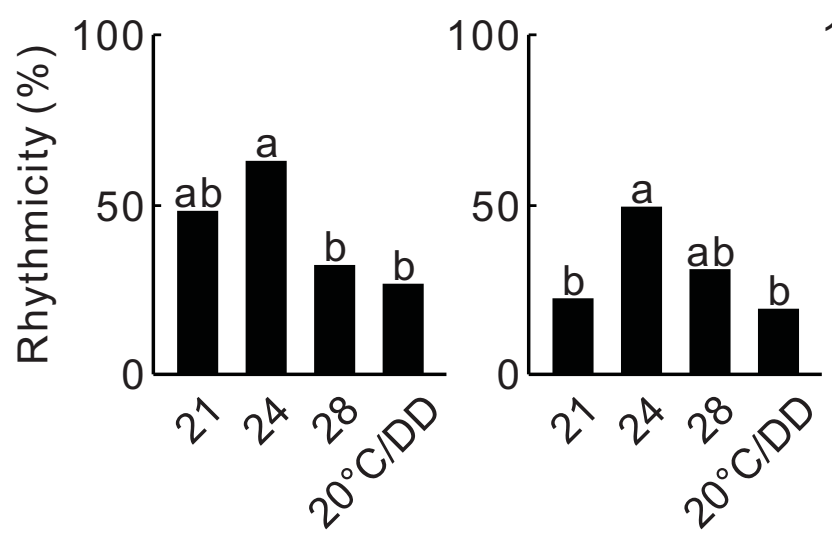

$C / k^{\text {Jrk }}$

Conditions 